\title{
Resilience
}

\section{Is resilience a normative concept?}

\section{Henrik Thorén \& Lennart Olsson}

To cite this article: Henrik Thorén \& Lennart Olsson (2017): Is resilience a normative concept?, Resilience, DOI: 10.1080/21693293.2017.1406842

To link to this article: https://doi.org/10.1080/21693293.2017.1406842

\section{Published online: 29 Nov 2017.}

Submit your article to this journal ๘

\section{Џ Article views: 55}

Q View related articles ¿

View Crossmark data ¿ 


\title{
Is resilience a normative concept?
}

\author{
Henrik Thorén (D) and Lennart Olsson \\ Lund University Centre for Sustainability Studies, Lund, Sweden
}

\begin{abstract}
In this paper, we engage with the question of the normative content of the resilience concept. The issues are approached in two consecutive steps. First, we proceed from a narrow construal of the resilience concept - as the ability of a system to absorb a disturbance - and show that under an analysis of normative concepts as evaluative concepts resilience comes out as descriptive. In the second part of the paper, we argue that (1) for systems of interest (primarily social systems or system with a social component) we seem to have options with respect to how they are described and (2) that this matters for what is to be taken as a sign of resilience as opposed to a sign of the lack of resilience for such systems. We discuss the implications of this for how the concept should be applied in practice and suggest that users of the resilience concept face a choice between versions of the concept that are either ontologically or normatively charged.
\end{abstract}

\section{KEYWORDS}

Resilience; normativity; concepts

\section{Introduction}

In this paper, we shall concern ourselves with the question of whether the concept of resilience - that has now so thoroughly permeated scientific and political discourse on issues ranging from sustainability and climate adaptation to national security and international relations - is a normative concept or not. Or somewhat more broadly put, to what extent (and in what way) its use commits the user to a certain set of values. We will argue that even when assuming a descriptive version of the resilience concept, the application of the concept in practice will in most or all relevant instances involve either far-reaching ontological or normative assumptions about the nature of the underlying system. The issue becomes particularly acute with respect to social systems or systems with social components.

We will argue that the way norms and values enter into how systems are construed matters for many applications, and relates closely to the observation that the application of the resilience concept sometimes appears to be curiously unstable (see e.g. Thorén, 2014). Should we understand the migration of a community following a series of severe storms as an adaptation to climate change and hence a reason to think that the community is resilient, or should we think of the dispersion of people as the collapse of the community, thereby understanding the situation as one where that community is not resilient (or not resilient enough) with respect to that particular kind of impact. The concept of resilience, on its own, 
says nothing about which way to go. The matter hinges on how the underlying system is understood, and small nuances here imply opposing interpretations of a materially identical situation. If being in a certain physical location (or returning to that location) is considered essential (or a proxy for something essential) then migration equals collapse. On an alternative construal, migration - even permanent migration - can be perceived as an adaptation and hence exemplifying the resilience of the community. For the kinds of systems to which resilience is applied and is thought to be informative about - urban areas, coastal cities, communities, countries, and so on - it is far from obvious how this construal is to be made.

The role of values and the normative content of the resilience concept has indeed been subject to much discussion. For some, the descriptive nature of the concept is taken as a given (see Derissen, Quaas, \& Baumgärtner, 2011), whereas others have maintained that the concept is normative or at least implicitly normative (Jerneck \& Olsson, 2008; Olsson, Jerneck, Thoren, Persson, \& O'Byrne, 2015). Brand and Jax (2007) in a frequently cited overview argue that there are many different resilience concepts, some normative, some descriptive, and some a form of hybrid concept that share features from both normative and descriptive versions. Original formulations, such as that found in Holling (1973) are argued to be descriptive, whereas many of the more recent - and often quite different - definitions fall under normative and hybrid categories.

The issue is neither scientifically peripheral nor otherwise moot. Operationally it has been taken to be of concern as it constrains admissible analyses of conceptual connections. Derissen et al. (2011), for instance, argue that the equivalence that is sometimes assumed between resilience and sustainability does not hold, precisely because the former is a descriptive concept and the latter is normative. More generally, confusing normative versions of the concept for descriptive ones are misleading, obscuring underlying value judgments and giving them the air of scientific objectivity (c.f. Newton, 2016). Indeed, an important concern, among those who have been critical about the widespread adoption of the resilience concept in science and policy-making, is that it serves specific ideological ends. This concern relates especially to the way the concept of resilience, and the resilience framework, fit with neoliberal discourse and governance (Chandler, 2012; Jerneck \& Olsson, 2008; Joseph, 2013; Olsson et al., 2015; Walker \& Cooper, 2011; Zebrowski, 2013). The charge gains force from the implicit nature of these assumptions and the way in which resilience discourse is often presented as disengaged and neutral, thereby suggesting little room for intellectual and practical alternatives.

Proponents of the concept - to the extent to which they have at all commented on the matter - have maintained that the concept is descriptive, although their target, for the most part, seems to be evaluative rather than ideological uses of it. ${ }^{1}$ A recurrent point is that resilience is not in itself valuable; whether it is good for something to be resilient depends on what that is (see e.g. Carpenter, Walker, Anderies, \& Abel, 2001). In this way resilience theorists perceive themselves as being engaged merely in reporting on the facts, leaving the value issues to others.

We will argue in support of two theses. The first is that the common, and arguably most relevant, construal of the concept of resilience is that it is a descriptive notion, at least on a standard understanding of the normative/descriptive distinction. This is not a particularly controversial idea.

The second thesis - which is the main focus of this paper - is that values do play an important role in applying the concept in many concrete situations. More specifically, we 
argue that (1) what comes out as signalling the resilience of a given system is extremely sensitive to how persistence is understood for that system and (2) for systems that invite contradictory understandings of persistence. What counts as resilience on one construal, comes out as the lack of resilience on the other.

We argue that using the resilience concept, in particular for social phenomena, typically demands high sensitivity with respect to how persistence is understood for that particular system, as compared to when discussing natural systems. The reasons for this, we propose, have to do with both the ontology of the systems themselves, and the combination of heterogeneous values surrounding what is important and central about the system in question and/or a lack of conventions surrounding how the underlying system is to be described. Another way to put the point is as follows. Application of an abstract concept like resilience relies on the implicit or explicit presence of a normative or ontological framework that answers questions about what is important or central about the systems to which the concept is applied.

Our approach differs from some other analyses of the notion of resilience, in particular those engaged with the broader discourse, such as Joseph (2013), Chandler (2012) or Zebrowski (2013), that seek to relate the resilience concept to broader intellectual and political discourse and historical trends, in order to explain the proliferation of the concept in terms of that fit. We seek to locate where values come into play even under the most'favourable' conditions.

The paper is structured as follows. We will begin by discussing the concept of resilience and give a basic definition from which we will then take our departure in the remainder of the paper. We then move to present an analysis of normative concepts in terms of evaluative concepts and apply this analysis to the concept of resilience arguing that resilience - on this analysis - is a descriptive concept. That is the first part of the paper. The second part of the paper involves first showing that the concept of resilience, even in its descriptive form, is highly sensitive to how the underlying system is construed, and then arguing that for social systems and systems with social components this underlying construal involves an input of values.

\section{The many concepts of resilience}

Several studies that have now appeared have compiled different definitions of resilience in the literature (Brand \& Jax, 2007; Klein, Nicholls, \& Thomalla, 2003; Meerow, Newell, \& Stults, 2016; Newton, 2016; see also Strunz, 2012; Thorén, 2014). It is patently clear that there exist not just one but many concepts of resilience. Moreover, it is noteworthy that some current definitions are highly complex making them difficult to subject to proper analysis on their own terms. Folke et al. (2002), for instance, define resilience as 'related to (i) the magnitude of shock that the system can absorb and remain within a given state; (ii) the degree to which the system is capable of self-organisation and (iii) the degree to which the system can build capacity for learning and adaptation' (Folke et al., 2002, p. 438). The definition mixes features that apply to states of systems, with those that apply to systems as a whole, and contain several further notions that are left largely without further development, concepts such as self-organisation, learning and adaptation.

Moreover, opinions differ not only on how to approach this plethora of different versions of the concept, but also regarding how it is to be assessed. Klein et al. (2003) conclude in an 
often cited passage that '[a]fter thirty years of academic analysis and debate, the definition of resilience has become so broad as to render it almost meaningless' (Klein et al., 2003, p. 42). Others, like for instance Strunz (2012), have highlighted the merits of vague concepts. Yet others have suggested that the substance of the concept is beside the point (Joseph, 2013). Those who have adopted the concept, especially perhaps in the discourse located at the intersection of science and policy, care less about the theoretical underpinnings provided that the concept serves certain ends.

Our strategy is to target a narrower version of the concept that is (i) true to its origins, (ii) compatible with many later versions of the concept (see Thorén, 2014) and (iii) defensible from the perspective of many of the proponents of the concept. Idealising the concept and its use in this way limits, to some extent, the scope of the conclusions but it also makes it possible to engage with the notion in more detail. The conclusions, we believe, also have bearing on many similar versions of the resilience concept, as well as those that depend on notions like adaptation and persistence.

We are going to understand resilience as the ability of a system to absorb a disturbance whilst retaining, through that disturbance, some property or set of properties. For convenience and clarity we will use this definitional schema, borrowed from Thorén (2014, p. 311), which is reproduced here below. ${ }^{2}$

Definition: Resilience is the ability of a system $\boldsymbol{S}$ to absorb some disturbance $\boldsymbol{D}$ whilst maintaining property $I$.

What it means is the following: a system $\boldsymbol{S}$ is resilient if, and only if, when subjected to some disturbance $\boldsymbol{D}, \boldsymbol{I}$ is maintained through the disturbance. Stability, against which resilience is usually contrasted, as Holling initially construes it (1973), pertains to the return to some reference state after some disturbance and does not involve keeping a given set of variables or a given property fixed through the disturbance. Later Holling was to change his mind and to opt instead for a different terminology, using the terms 'engineering resilience' and 'ecological resilience' (Holling, 1996). The underlying concepts remained the same however. ${ }^{3}$

The $\boldsymbol{I}$ in the schema may represent the value of a parameter, but also a certain function or structure of a system. It need not be something that should, or even can, be quantified, but may pertain to purely qualitative features. On a broad interpretation the $I$ stands for the identity of the system; if $\boldsymbol{I}$ is maintained the system is the same. However, for the most part, identity in itself is not particularly informative. Further construal is necessary, and in certain situations, operationalisation. ${ }^{4}$

To specify the I for a given system is to give persistence criteria for that system. A concept of resilience can operate with explicit or implicit persistence criteria. ${ }^{5}$ It is rare that persistence criteria are given unambiguously, even when they are explicit. Folke et al's definition above, for instance, seems to suggest that it is a matter of staying within a given state, an idea that in many cases will be much too narrow. Adger, Hughes, Folke, Carpenter, and Rockström (2005) consider resilience of linked social-ecological systems to be the capacity to 'absorb recurrent disturbances such as hurricanes or floods so as to retain essential structures, processes, and feedbacks' (p. 1036). Here, retaining essential structures, processes and feedbacks are the persistence criteria. If no persistence criteria are given at all, the identity of the underlying system is simply assumed or stipulated at the outset. It is not uncommon to make a leap directly from more abstract and sometimes vague characterisations to measurable proxies (resilience has turned out to be notoriously difficult to operationalise, see Newton, 
2016). When analysing the resilience of New Orleans in the context of hurricane Katrina, Burton (2015), for instance, extracts from a wish list of 130 variables potentially linked to resilience, 98 that are actually collected. By analysing the large correlation matrix we can get an idea of what kind of identity (I) the system at hand (New Orleans) would be. A resilient New Orleans should (among many other characteristics) be composed of young, healthy, fit, English speaking, not racially segregated, well-educated people owning their own (not mobile) house and a car.

Moving to the $\boldsymbol{D}$ in the schema, it is sometimes useful to think of disturbances, the $\boldsymbol{D}$ in the schema, as having (for lack of a better set of terms) a system-side and a world-side component (not to be confused with the distinction between endogenous and exogenous disturbances). For example, for real systems, it is usually obvious that a given disturbance exists independently of the system which is disturbed and has its own ontology. The hurricane that hits a coastal area, or the drought spell that befalls an agricultural community, can be described on their own terms. But if $\boldsymbol{D}$ is a disturbance of $\boldsymbol{S}$ then it follows from the very meaning of the notion of disturbance that $\boldsymbol{D}$, in one way or the other, actually impinges on $\boldsymbol{S}$ in some respect. Otherwise, another why talk of a disturbance at all? An office chair is not psychologically resilient to being chastised on social media - even if one gives the chair a facebook account - since they are not affected by that sort of thing in the first place. Hence, if $\boldsymbol{D}$ is a disturbance of $\boldsymbol{S}$ then $\boldsymbol{D}$ has some effect on $\boldsymbol{S}$. Whether one finds it natural to focus on the system-side or the world-side component of a given disturbance depends on the context. ${ }^{6}$ For now, two comments are in order.

First, it is possible to think of this system-side component as an adaptation to the disturbance, at least on a minimal understanding of that notion. Notably, resilience theorists often highlight precisely this aspect of the concept; resilient systems are flexible, indeed their flexibility is often constitutive of their resilience (see e.g. Folke et al., 2010). In general terms, being flexible in one respect (e.g. for some set of parameters) is what allows a system to keep something else fixed. Consider a variation of a common analogy. Suppose we compare two very rudimentary 'systems'; an egg and a tennis ball. Assume further that for both systems, the $\boldsymbol{I}$ in question is the structural property of having an unbroken outer shell, and the $\boldsymbol{D}$ is some form of unevenly distributed pressure on the outer shell, such as will arise when one squeezes the egg or the tennis ball with two fingers. The tennis ball will be more resilient than the egg in the sense that it will retain its structural integrity under greater pressures. ${ }^{7}$ The reason is that it has a flexible outer shell. The egg, on the other hand, has a rigid and brittle outer shell. In a sense the tennis ball adapts to the disturbance.

Second, if we think of resilience as keeping something fixed through a disturbance, there has to be some separation between that which accounts for the continuity of the system, and that which is disturbed. This is a conceptual prerequisite; it is otherwise not possible to talk about resilience for the system in the given sense. ${ }^{8}$ For instance, we might be interested in the resilience of a function - i.e. the $\boldsymbol{I}$ is understood as maintaining this function - under structural disturbances or changes. An economy might be deemed resilient if it maintains economic output through shifts from relying on one sector to relying on another. What it means to disturb a system is thus closely related to, or dependent on, what persistence of that system is taken to be. We will return to this in more detail below.

Without getting too far ahead of ourselves the point is that there is some room for interpreting and deploying the supporting concepts on which the resilience concept relies in different ways. Broadly speaking, it is hard to give general prescriptions regarding how 
specific one should be, for instance with respect to formulating persistence criteria. It depends, among other things, on the needs, intentions and interests of those deploying the term; if one is seeking to explain an event, predict the behaviour of some system, compare features of two systems, devise interventions, or merely produce interesting hypotheses, all require different degrees of precision and hence involve different ontological and epistemological commitments.

\section{Descriptive and normative concepts}

Now, we move to a brief discussion of the distinction between normative and descriptive concepts. It is interesting to note that few of those who have commented on the normative or descriptive status of the resilience concept have explained more precisely what they mean by this assertion. Brand and Jax (2007), for example, expand on the substance of this, to them central, distinction, only by noting that '[t]his [the ambiguous uses of the resilience concept] is due to the blending of descriptive aspects, i.e. specifications of what is the case, and normative aspects, i.e. prescriptions [of] what ought to be the case or is desirable as such' (Brand \& Jax, 2007). In this paper, we shall begin by giving a somewhat fuller overview of this distinction.

One way of analysing normative concepts is as evaluative concepts. Such concepts are commonly taken to function in the following way: they provide reason for action whilst their correct application does not depend on the world being in any particular state, i.e. evaluative concepts are action guiding but not world-guided (see Williams, 2006). In this category, we find familiar notions such as GOOD and WRONG. What is good or wrong depends on the values of a particular person or group, not on a certain state-of-affairs. To some jogging and early mornings are good, to others this is not so. So whether it is suitable to talk of the good or the wrong just depends on how one feels about these things, not whether they are present or not.

Descriptive concepts, on the other hand, function in the opposite way; they provide no reason for action, but their correct application very much depends on how the world is. Again, in the words of Bernard Williams, they are world-guided but not action-guiding. In this category, we find a vast array of concepts such as SMALL and MORNING and ELECTRON. This is the basic distinction.

Beyond these two categories there appears to be a further class of concepts that blends the distinctive features of both descriptive and evaluative concepts; i.e. these concepts provide both reasons for action and tell us something about how the world is. Williams calls these concepts thick evaluative concepts, to be contrasted against thin evaluative concepts (i.e. concepts that are purely evaluative). Paradigmatic examples of thick evaluative concepts are COURAGE, CRUELTY or KINDNESS (Williams, 2006, 140-142).

In the following, we assume it is possible (contra e.g. Wittgenstein) to distinguish between using a concept as if it were normative, and using a normative concept. The motivation here is mainly methodological - we are not trying to engage immediately in more fundamental theories about the nature of concepts. We are assuming that confusion with respect to the normative content of the resilience concept is not a trivial matter of confusing two identical labels with one another. It is beyond doubt that the resilience concept is indeed sometimes used as if it were a normative concept. ${ }^{9}$ 
In other words, we are going perceive of this concept on its own terms, and for the purpose of the present argument departs from the assumption that definitions and characterisations do matter. This much should be obvious from the extraordinary amount of literature that turns on precisely this and the common complaint that conceptual imprecision is indeed a problem (Klein et al., 2003; Newton, 2016). In this respect, we differ from e.g. Joseph (2013) in his suggestion that any philosophical approach to the concept lends unwarranted legitimacy to underlying ideological assumptions.

\section{Resilience as an evaluative concept}

Is resilience in the sense we have introduced it above normative? On the above analysis of normativity that would mean that it is either a thin or a thick evaluative concept. That it would be a thin evaluative concept is immediately false. Then the concept would have no descriptive content at all. There is, of course, nothing to stop anyone from using the concept as a thin descriptive concept in the same way as there is nothing that stops people from calling war'peace' or tables 'chairs'. Here, however, we shall disregard those kinds of breaches of basic linguistic conduct.

Moving on, the idea of resilience as a thick evaluative concept then seems at least prima facie more enticing and promising. It is nonetheless problematic, for quite obvious reasons. For one, and at least for our narrow conception, whether resilience is good or bad depends on what it is that is resilient. Resilient oppression -> BAD. Resilient democracy $->$ GOOD. Compared with paradigmatic examples, like courage, the difference becomes clear. To be courageous can never in itself be bad, even if the outcome of some particular person's disposition to be courageous may have detrimental consequences for that person (or others).

So, resilience, reasonably, should be considered to be a descriptive concept on this account. For the sake of argument, however, let us examine the resilience concepts that Brand and Jax (2007) file under the normative category in their overview of different resilience concepts. In this more general category, we find two further subcategories: metaphorical definitions and sustainability-related definitions. They offer one example of each of these. These are resilience as flexibility over the long run, and resilience as maintenance of natural capital in the long run, respectively. Let us focus on these. Are such understandings of resilience normative? Well, taken at face value it would seem not. Whether flexibility over the long term is good depends, of course, on what it is that is flexible. As for maintenance of natural capital in the long term, it is probably desirable from a range of perspectives, but there are exceptions. For someone that is expecting the end of the world, then maintenance of natural capital in the long run may be considered wasteful. For cornucopian economists, like Julian Simon (see e.g. Simon, 1996) or Robert Solow (see e.g. Solow, 1993), there are other reasons not to save natural capital (since it can be converted elastically into man-made capital).

So, why then, would Brand and Jax think these concepts are normative? Presumably since they are used as if they were evaluative or denoting properties 'viewed as desirable as such' (Brand \& Jax, 2007). Here, we can note that flexibility in the long run is a property that happens to be beneficial, with respect to the particular type of system in question, in a wide range of contexts. ${ }^{10}$ As for the second definition, something similar could be said. Brand and Jax suggest that those who deploy resilience in that way consider that keeping the 
life-support system of the planet going is a universal good. But this too, as the above examples indicate, is false.

To conclude this section, at least for the narrow conception of resilience, it seems fairly straightforward to make the case that it is indeed a descriptive concept, at least in the sense proposed by Bernard Williams. Resilience, on the understanding we have proposed, appears to indicate a property of a system not an evaluative claim about that system. Whether the resilience of $\boldsymbol{S}$ is desirable or not, depends simply on what $\boldsymbol{S}$ is.

So are we now just begging the question? We have effectively excluded - by means of stipulation no less - precisely the kinds of concepts that may well be normative. The answer to the question posed in the title of this paper thus comes out in the negative, but it does so for seemingly trivial reasons.

Instead of settling here, we are going to take this as a point of departure. In what follows, we shall make the following assumption: the apparent disagreement on the normative status of the resilience concept cannot be resolved by reference to different resilience concepts, some normative and some descriptive. We will then argue that it is in application to particular kinds of systems that values come into play in ways that may matter.

\section{Resilience and persistence}

Before we circle back to issues of normativity, let us return to the issue of persistence. We have already argued that it is conceptually necessary for the kind of resilience concept we have taken an interest in here. This is hardly news. Persistence has been an important concept in understanding resilience since the beginning; Holling himself even suggested that resilience can be understood as the probability of persistence (Holling, 1973). ${ }^{11}$ Here is one way to make sense of this relationship. Let us return to the definitional schema above and give some attention to the $\boldsymbol{I}$ in that formula. If $\boldsymbol{I}$ is maintained over a period of time - or if it is a variable that remains constant within some interval - then the system can be considered persistent through that period of time. If there is a disturbance of the system within that time interval and this disturbance does not, or does not sufficiently, affect $I$, then the system is resilient. However, as argued above, since the system is disturbed something about the system must have changed or been affected somehow.

Now, it is notable that persistence, in this sense, is important in analyses that rely on a resilience concept in line with the one we have here adopted. The point is this: unless we have reason to think that whatever it is that we are looking at is indeed the same thing, then the notion of resilience is rendered more or less useless since we cannot adequately differentiate between the system adapting and the system collapsing. Consider two brief examples.

The first one is from psychology where the concept of resilience has been important for at least as long as it has been in ecology (Thorén, 2014). It occurs in similar senses and similar conceptual concerns have arisen. When psychologists use the term 'resilience', they sometimes refer to resilience as the ability to maintain normal function during a traumatic event such as the loss of a close friend or relative. ${ }^{12}$ In this case, normal function serves as the $I$ and the traumatic event as the $\boldsymbol{D}$ in the formula. Now, astonishingly, it has been argued that common, although disruptive responses to such traumatic events, like depression, are not in fact the system collapsing, but are rather to be viewed as adaptations. That is to say, they may well be a sign of the resilience of the individual (its 'price'), rather than the lack of 
resilience (Rutter, 1993). Rutter finds this idea objectionable and misleading, but nonetheless, it goes to show that it has not always been apparent how to understand these situations. So one way of construing this apparent disagreement is as a disagreement over what constitutes the $\boldsymbol{I}$ in the formula for the given system.

The second example is a little closer to home for sustainability scientists but perfectly analogous with the one just presented. One topic that has been of some interest in the discussions on the resilience of coastal communities is the role of migration as a response to, say, severe floods (Adger, 2000). Now, suppose a given coastal community is hit by a flood resulting in the displacement of that community. Is it resilient or not? That depends on what we consider the continued existence of that community to be constituted by. If persistence is conditioned on the community staying in a certain location, then by all means, the community has collapsed. But if we abandon this particular persistence criterion and opt for something else - say the continued interaction of the individuals within the community, or their well-being - we might think of this case of migration as an adaptation, and thus an indicator of the resilience of the community. Adger attempts to get out of this by differentiating between types of migration; in short, seasonal or circular migration is treated as a sign of resilience, whereas'population displacement is often an indicator of the breakdown of social resilience' (Adger, 2000, p. 357). Others, however, have argued that even displacement on a massive scale, like the exodus following the Dust Bowl was in fact an adaptation to a changing climate (McLeman \& Smit, 2006). We do not mean to suggest that either perspective here is entirely unreasonable generally speaking, but merely mean to highlight that depending on what we consider to be essential to the system, the $I$ in our formula, one and the same thing may come out as either a sign of the presence of resilience or a sign of the absence of resilience. That is to say, the concept of resilience as such is no arbiter here.

Along these lines, we can construct examples that appear increasingly, and more obviously, absurd. Is the recent Syrian diaspora an adaptation to a prolonged and brutal civil war or the collapse of civil society? Is desertification an adaptation to a drier and warmer climate or systemic collapse? Two points are due at this juncture. The first is that applying the resilience concept to a system relies on an idea of what persistence in the system is. This sensitivity to how the system is described can be dramatic, as the above examples show. One and the same situation can, depending on how we perceive of the system, be taken to indicate the presence of resilience in the system or the absence of the same.

Second, there appear to be relevant cases - for example when we apply the resilience concept to communities, cities, countries and so on - where there are alternative ways of describing a system.

\section{Ontology and axiology in the application of the resilience concept}

First some terminology. A system description is here understood as e.g. establishing or determining system boundaries, driving parameters, etc. One important function that formulating a system description serves is precisely giving (or implying) the persistence criteria for a specific system. An admissible system description here is a description that is valid or true or accurate or helpful, etc. ${ }^{13}$

Now, to recap. The argument so far is that (1) determining what persistence means for a particular system (providing a system description) has considerable impact on how resilience is to be understood for that system and (2) often we appear to have alternatives that yield 
understandings of resilience that differ in significant ways. That is, depending on what is deemed to be central to a particular system, different system descriptions (ways of fixing $I$ in the schema) become applicable. The upshot of this argument is that any application of resilience also implies some construal or assumption of what actually constitutes system persistence, or at least an idea that the system is in fact the same. That construal may be muddled, implicit or badly grounded to be sure, but nonetheless is present.

The examples we have provided thus far suggest that judgements regarding the identity of a particular system are at least sometimes informed by the interests of the observer (rather than the nature of the system). In the remainder of this section, we shall focus on (2). The reason is that much turns on the idea that there are several admissible descriptions for a given system. If indeed for any system, or at least any system of interest, there is only one admissible description then the whole issue of different perspectives is invalid. Suppose we call this view - i.e. that there is only one admissible description for a given system ${ }^{14}$-'systems monism'. We may then call the view that denies this simple tenet 'systems pluralism'.

The foundations of either view are rooted in deeper philosophical concerns and depend on a range of issues, including how admissibility is construed, what a system is, how systems are individuated, how science at large connects to the world it purports to explain, and so on. Here, we simply note that systems monism has substantive epistemological and ontological implications and it is a thesis that is far from obvious.

Conceived of as a general proposition; i.e. that all systems are such that they have only one admissible description, it seems far-fetched; the examples provided above suggest as much. ${ }^{15}$ As a more limited proposition, however, perhaps constrained to apply only to, say, complex adaptive systems for instance, it arguably gains in plausibility. Other problems then arise, however. One is that one is committed to the idea that e.g. social systems are complex adaptive systems and that complex adaptive system make out a genuine (natural) category. This is something that many resilience theorists may well be willing to do (Gunderson \& Holling, 2002, Walker \& Salt, 2012), but again, if we use the examples above, the mere presence of alternatives appears to indicate that claim is false for at least some of the systems resilience that theorists are interested in. ${ }^{16}$

At any rate, there is an ontological dimension to take into account. It is at least conceivable that there are systems that conform to the systems monist's expectations. Here, it serves to note that it is not necessary for the observer to know precisely what constitutes persistence in $\boldsymbol{S}$, it is sufficient to know (or anyway, suspect) that $\boldsymbol{S}$ has persisted. This in itself, however, involves ontological assumptions that will in practice often go beyond what the situation affords. That is, there are plenty of situations where the resilience concept at least prima facie seems serviceable where such ontological commitments are inappropriate. For the monist, then, the resilience concept is descriptive in a deep sense, but the price for this descriptiveness is steep.

The pluralist faces a different challenge. Here, the appropriate application of the resilience concept depends on the perspective one takes on the system under scrutiny. This perspective is unavoidably connected to the interests and values from which that perspective departs. One way of construing a system casts the system as resilient and adaptive, another as lacking resilience and fragile. The pluralist is less constrained by some particular ontological framework, or substantive assumptions about the underlying system, but rather relies on a normative or axiological framework that guides the picking of one perspective over another. ${ }^{17}$ Or, she commits to a substantive and consequential epistemological modesty. There can 
always be a different perspectives that re-arranges the pieces of the board. The resilience concept here is only really descriptive if one disregards this underlying framework. ${ }^{18}$ For the pluralist approach to social systems, it can never be solely about reporting on the facts but also always about highlighting what it is that is important in a broader sense: What kind of society do we want? What is a good or decent life?

Herein lies a kind of dilemma; confronting - embracing even - the value ladenness of the resilience concept, or accepting its ontological implications and the potential problems that come with those implications (see e.g. Olsson et al., 2015).

Now, assuming a pluralist view of social systems it is notable that what makes this potentially difficult is not merely that several different admissible descriptions are available. There are often many ways of describing a system, even when they are strikingly simple. Notably, putting the resilience concept to use, even within ecology, rests on a range of idealisations and specifications, all of which are far from obvious. To realise this is so one only has to return to Holling's original text and examine the models he relies on (two species predator-prey models), the choice of empirical examples (well-bounded lake ecosystems), and the representations he picks and operationalises the concept over. Even in that case, where the underlying ontology presumably is comparatively clear, the concept only really becomes applicable once all those components have been deployed. Where the world fails to reassert itself, convention can do the job. For social systems, in particular, the lack of stable and broadly acceptable conventions is much more acute and the prospects of ever arriving at such conventions slimmer. The reason is simple, of course: it is not a question for science to sort out what, ultimately, is central or important about social systems.

The danger, to our minds, rests in approaching resilience from the monist perspective even when the pluralist proviso would have been more appropriate. Such an error involves both the introduction of unwarranted ontological claims, and the failure to recognise the values that go into construing the underlying systems. A particularly clear example of this can be found in the recent Arctic Resilience Report (Arctic Council, 2016). The Arctic region is one where the effects of climate change will be particularly severe. In many places these effects are already felt. The report contains, among other things, a wealth of case studies of resilient behaviours on the part of various inhabitants of the region. For example, how the Skolt Sámi communities of Näätämö River between Finland and Norway have adapted to pressures from climate change, mining and tourism, or how the 'ability and willingness to move' among the inhabitants of Kiruna, Sweden, as a consequence of the mining operation upon which the town once was built 'demonstrates resilience, despite the economic, technical and social difficulties' (Arctic Council, 2016, p. 103) and so on. It is interesting to note that the report has been subject to popular debate that appears to turn on precisely the kinds of conceptual issues that we have here raised; critics have suggested that the characterisation of the observed responses as adaptations and signs of the resilience of local communities and groups might equally well be viewed as the collapse and subordination of these communities (Reid \& Skoglund, 2017).

As noted in the introduction, resilience is sometimes criticised as giving scientific legitimacy to neoliberalism. If the nature of the disturbance changes, resilience may also change its normative character. If a social-ecological system, such as the aforementioned Sàmi community, has in the past been highly resilient by adapting to natural disturbances this is usually seen as positive and politically neutral. If the nature of disturbances changes, from natural (e.g. storms, floods, droughts etc.) to social (e.g. mining, wind power, logging, etc), being 
resilient could become highly political. The second part of the definition of resilience in the Arctic Resilience Report contains 'when necessary transform'. This could be taken as a political message - don't fight for your rights to reindeer rangelands. This ('when necessary, transform') is of course very closely related to the identity ( $\boldsymbol{I})$ of the system, If being Sami is primarily about the pastoral livelihood, then the resilience is low since access to reindeer rangelands has been reduced due to external social and economic interests. If the identity is primarily about speaking the language, the Sami are a resilient ethnic group because the Sami language(s) have been formally recognised by governments, an increasing number of people speak the language, there are an increasing number of courses, etc. So being resilient or not becomes primarily a matter of the willingness to accept a change of identity - which of course is a hugely controversial issue.

The underlying values that guide how we think of systems make analyses in terms of resilience vary across the entire spectrum of possibilities, at least if one is willing to go beyond extinction events. To permit ourselves a topical example, let us consider for instance the US election campaign of 2016. The contrast in how the country was presented by the antagonists of that election could not have been sharper. Donald Trump's campaign portrayed the US as under siege, teetering on the verge of collapse, whereas Hillary Clinton offered a picture of a country motoring along under steady (although perhaps too slow) progress. Similarly contrasting narratives were offered by Leave and Remain sides in the Brexit vote. Now, although some of the disagreements that occurred in these elections were about facts, others clearly had to do with differing perceptions of what is central to one's particular nation that bottoms out in a given set of values. On some descriptions collapse seems imminent, on others, persistence reigns.

Two final remarks before we close this section. First, one way of understanding the points made above is in terms of the risks - epistemic and otherwise - involved in using the concept of resilience without paying attention to how persistence and adaptation are construed within the system. There are two immediately apparent such risks. One renders the concept, to speak metaphorically, too'roomy' in specific applications. If the system description is not sufficiently precise there may be ways of construing resilience that will seem ambiguous or even contradictory. The other risk has to do with, perhaps inadvertently (or at least implicitly), committing to a very specific and narrow understanding of persistence. The problem here is that a notion of resilience that relies on a specific, but tacit, understanding of what is important or central in a given system, makes that version of the concept carry very specific implications. In some contexts this can be highly inappropriate.

Second, to return to one of our initial questions. How come there is disagreement about the normativity of the resilience concept in the first place? This analysis suggests that one way of disambiguating the apparent disagreement between those who think of the concept of resilience as descriptive and those who suggest it is a normative concept has to do with what one includes in the construal of the concept. For some, the construal of the underlying system is part of the conceptualisation, whereas others do not take that construal into consideration. In the latter case, the concept of resilience appears to be wholly descriptive and scientifically unproblematic.

\section{Concluding remarks}

In summary, if the gist of the above argumentation is accepted, and we return to the issue of whether the concept of resilience is normative or not, the conclusion to be drawn from 
this must be that given that the system is fixed ( $\boldsymbol{I}$ is determined for a given system $\boldsymbol{S}$ ) then resilience is a descriptive concept in the sense that whether or not to apply the term is determined by the nature of the world. For example, if we stipulate that having a sufficient number of members in physical proximity to a certain location is what it means for a particular community to exist, then we can in no uncertain terms discuss that community's resilience to various types of disturbances. Migration is collapse. If the description is fixed, then the appropriate use of the term resilience depends on how that community reacts (with respect to their spatial distribution) to impacts. However, this does not 'save' the concept from value ladenness. The use of the concept hinges on some construal of the underlying system. This construal, in turn, relies on normative and/or ontological assumptions about that system. This is particularly clear with respect to social systems.

Another way to phrase this is that the application of the concept to a concrete situation relies on some normative or ontological framework. We have suggested that the resilience theorist is faced with a kind of dilemma; to commit either to far-reaching ontological claims, or to some set of values and norms with respect to the systems under scrutiny. Whether this is ultimately a problem or not depends on both the nature of the systems themselves - the ontological homogeneity of the categories upon which resilience theorists often rely, categories like complex adaptive system - and on the values and interest that go into highlighting some features of our social world at the expense of others.

The danger is quite clear and has been highlighted before. The assumption that resilience is a kind of natural property of systems gives the concept a sheen of scientific objectivity that is in certain contexts unwarranted or even outright dangerous, if one takes the policy that may follow into account.

A few final remarks. First, we do not mean to suggest that all-out relativism reigns. All system descriptions are not equal, some are more reasonable than others and there are clearly situations where there are no meaningful ontological disputes. We merely want to point to the fact that, even under favourable conditions, there are options that make a great deal of difference as regards how resilience is subsequently to be understood. If one is willing to accept the basic terminology of resilience at the outset, then one will have to settle with a much messier, overlapping and value-charged account of social systems.

Second, neither do we suggest that resilience necessarily needs to be scrapped as a concept. In the above given understanding it is under certain conditions a perfectly serviceable notion that can be elucidating, presumably even for social phenomena. What we propose, rather, is an awareness of the values that are often a necessary part of applying the concept to particular cases and a certain degree of epistemological modesty. Here, our pluralist intuitions lead us to think that the many possible ways of thinking of social systems is not going to go away; it is not merely an artefact of our lack of understanding. The resilience theorist, it seems to us, will either have to accept a much thinner concept of resilience, or to embrace fully the ontological and normative implications that inevitably come with more substantive versions. What we mean is that strong ontological commitments are not problematic if they turn out to be correct. Here, a strong, ontologically charged, concept of resilience has deep epistemological implications. For instance, inferences can be made across types of systems (natural to social), and certain types of models and modelling approaches becomes suitable. Weaker notions of resilience founded on a pluralist vision of the underlying systems are more applicable but less productive. 


\section{Notes}

1. Lance Gunderson pointed out, in a recent lecture at Lund University, that the concept is descriptive and took that to imply that it is not a good thing in itself. Otherwise this stance is to a considerable extent implicit in the approach, rather than explicitly defended. The idea seems to be that if resilience is descriptive then resilience theorists are merely engaged in the objective reporting on the facts. So normative conclusions from that process say, to build more resilience, are not believed to be tinted by any particular perspective.

2. The underlying intuition here appears to be rather widely shared, c.f. Carpenter et al. (2001).

3. The basic conceptual distinction is common, although the terms used differ. Schrader-Frechette and McCoy, for instance, prefer the terms 'dynamic balance' and 'persistence' (Shrader-Frechette \& McCoy, 1993), Orians (1975) uses the term 'inertia' as a label for what Holling calls'resilience' and Grimm and Wissel (1997) opts for'domain of attraction.'This is mostly a matter of terminological preference and the underlying concepts are more or less the same. More important here is the theoretical shift in ecology (and also economics) - spearheaded by ecologists like Holling - from an emphasis on stability and the dynamics of ecosystems close to equilibrium to a focus on dynamics far from equilibrium. An excellent overview of this shift can be found in Zebrowski (2013).

4. This has proved to be difficult with the resilience concept. Stability can easily be operationalised as the speed of return to the reference state, or the distance (with respect to some variable) between the state that is returned to and the reference state (see e.g. Newton, 2016).

5. Resilience theorists do explicitly talk of identities; Walker and Salt write that resilience is 'the capacity of a system to absorb disturbance and reorganize so as to retain essentially the same function, structure, and feedbacks - to have the same identity' (Walker \& Salt, 2012, p. 3).

6. If one is mainly concerned with highly idealised models where disturbances are stipulated to work on only very few variables, all disturbances are, for trivial reasons, qualitatively similar from within the system. For a real system, like a coastal community, however, there is often reason to differentiate between different kinds of disturbances.

7. Note that under alternative descriptions of the system, the tennis ball can be considered stable; for example, if $I$ is not thought of as structural integrity, but its shape. Moreover, what makes the tennis ball resilient under one assignment of $I$ is what makes it stable under another.

8. Notably we do not mean to suggest here that resilience can only be deployed meaningfully to systems that are fundamentally static. Indeed, in most of the literature on resilience the emphasis is on flexibility and change (see e.g. Folke et al., 2010). On a purely conceptual level, it makes no sense to talk of resilience if there is no continuity at all (c.f. Cumming \& Collier, 2005). What constitutes continuity for a given system, and how that is best determined given some set of (e.g. epistemological) constraints, is a different question.

9. Again, a good overview can be found in Brand and Jax (2007).

10. We are here taking a stance on these concepts that may appear to be strict to the point of misrepresenting them. The concept of resilience is commonly part of a larger system of ideas and within that larger system of ideas, flexibility in the long run in a very natural or obvious way comes out as something good or desirable. It is by being flexible that complex adaptive systems survive, so from the perspective of the systems themselves (or from within them), being flexible (or having adaptive capacity etc.) is a good thing. This is certainly the case and, without getting too far ahead of ourselves, this is a central part of the point of this paper. The commitment to this particular ontology is not always how the applicability of the concept of resilience is judged, and sometimes this commitment is explicitly downplayed. This is a source of confusion.

11. See also Folke et al. (2010).

12. Garmezy considers resilience to be 'Functional adequacy ... (the maintenance of competent functioning despite interfering emotionality) ... as the benchmark of resilient behaviour under stress' (as quoted in (Olsson, Bond, Burns, Vella-Brodrick, \& Sawyer, 2003, p. 3). See also (Rutter, 1993) for a discussion of different definitions of the resilience concept in psychology. 
13. Developing this concept is beyond the scope of this particular paper and what comes out as admissible or not to some extent depends on what fundamental philosophy of science one is inclined to subscribe to. The social constructivist and the naive realist may have rather different intuitions regarding how most systems are. That does not, however, change the fundamental tenets of this paper but merely offers a different way of discussing the matters so that the reader can feel free at this point to attach his or her favourite epistemology.

14. Another possibility here is that there are several admissible descriptions but they are all equivalent with respect to how resilience is construed. For simplicity, we file that category under systems monism.

15. System individuation matters here, although we shall not pursue that particular issue further. In brief, it is perhaps possible to argue that it is not a matter of several descriptions of one system, but rather several descriptions of several systems that just happen to overlap in certain respects.

16. The idea here would be that social-ecological systems are complex adaptive systems, and complex adaptive systems are a natural kind (for an introduction see Bird \& Tobin, 2017): a set of entities that share some essential properties. In other words, expanding the resilience framework to apply not only to ecosystems but also to social systems and social-ecological systems involves making a substantive claim about the nature of these systems, and the features they share. Whether or not resilience theorists indeed are of this view is a little uncertain; but it is in no way an implausible reading. Although resilience theorists sometimes emphasise the provisional nature of their framework - it is merely to be viewed as a heuristic device, or a metaphor (see e.g. Carpenter et al., 2001, p. 766; Holling \& Gunderson, 2002, p. 49) - the claim that social or social-ecological system just are complex adaptive systems, or self-organising systems, is virtually endemic (see e.g. Walker \& Salt, 2012).

17. There is a general epistemological argument to made for pluralism. Representations, such as scientific theories, concepts, and models, are inherently partial (see Kellert, Longino, \& Waters, 2006).

18. With pluralism follows epistemological modesty; the good pluralist acknowledges the limits under which he or she operates. It is notable that pluralism with respect to the models deployed by resilience theorists has been advocated before, see e.g. Cumming \& Collier, 2005.

\section{Disclosure statement}

No potential conflict of interest was reported by the authors.

\section{Notes on contributors}

Henrik Thorén holds a PhD in Theoretical Philosophy from Lund University and is currently on a post-doctoral fellowship at LUCSUS, Lund University. His doctoral thesis revolved around the philosophy of interdisciplinarity and interdisciplinary problem solving in sustainability science.

Lennart Olsson, professor of Geography at Lund University, was the founding Director of LUCSUS 2000-16. Current research focuses on the politics of climate change in the context of poverty, food insecurity and ill-health in sub-Saharan Africa. He was Coordinating Lead Author for the chapter on Livelihoods and Poverty in IPCC's 5th Assessment Report 2011-14 and the chapter on Land Degradation in the upcoming special IPCC report on Climate Change and Land (SRCCL), 2017-19.

\section{ORCID}

Henrik Thorén (iD) http://orcid.org/0000-0002-6356-2022

Lennart Olsson (iD http://orcid.org/0000-0001-8353-1074 


\section{References}

Adger, W. N. (2000). Social and ecological resilience: Are they related? Progress in Human Geography, 24(3), 347-364.

Adger, W. N., Hughes, T. P., Folke, C., Carpenter, S. R., \& Rockström, J. (2005). Social-ecological resilience to coastal disasters. Science, 309(5737), 1036-1039.

Arctic Council. (2016). Arctic Resilience Report. (M. Carson \& G. Peterson, Eds.). Stockholm: Stockholm Environment Institute and Stockholm Resilience Centre. http://www. arctic-council.org/arr

Bird, A., \& Tobin, E. (2017). Natural kinds. In E. N. Zalta (Ed.), The stanford encyclopedia of philosophy (2017 ed.). Retrieved from https://plato.stanford.edu/archives/spr2017/entries/natural-kinds/

Brand, F., \& Jax, K. (2007). Focusing the meaning (s) of resilience: Resilience as a descriptive concept and a boundary object. Ecology and Society, 12(1).

Burton, C. G. (2015). A validation of metrics for community resilience to natural hazards and disasters using the recovery from hurricane katrina as a case study. Annals of the Association of American Geographers, 105(1), 67-86.

Carpenter, S., Walker, B., Anderies, J. M., \& Abel, N. (2001). From metaphor to measurement: Resilience of what to what? Ecosystems, 4(8), 765-781.

Chandler, D. (2012). Resilience and human security: The post-interventionist paradigm. Security Dialogue, 43(3), 213-229.

Cumming, G. S., \& Collier, J. (2005). Change and identity in complex systems. Ecology and Society, 10(1).

Derissen, S., Quaas, M. F., \& Baumgärtner, S. (2011). The relationship between resilience and sustainability of ecological-economic systems. Ecological Economics, 70(6), 1121-1128.

Folke, C., Carpenter, S., Elmqvist, T., Gunderson, L., Holling, C., \& Walker, B. (2002). Resilience and sustainable development: Building adaptive capacity in a world of transformations. Journal Information, 31(5), 437-440.

Folke, C., Carpenter, S. R., Walker, B., Scheffer, M., Chapin, T., \& Rockström, J. (2010). Resilience thinking: Integrating resilience, adaptability and transformability. Ecology and Society, 15(4), 20.

Grimm, V., \& Wissel, C. (1997). Babel, or the ecological stability discussions: An inventory and analysis of terminology and a guide for avoiding confusion. Oecologia, 109(3), 323-334.

Gunderson, H., \& Holling, C. S. (eds.). (2002). Panarchy: Understanding transformations in human and natural systems. Washington, DC: Island Press.

Holling, C. S. (1973). Resilience and stability of ecological systems. Annual Review of Ecology and Systematics, 4(1), 1-23.

Holling, C. S. (1996). Engineering resilience versus ecological resilience. Engineering within ecological constraints, 31(1996), 32.

Holling, C. S., \& Gunderson, H. (2002). Resilience and adaptive cycles. In H. Gunderson \& C. S. Holling (Eds.), Panarchy: Understanding transformations in human and natural systems (pp. 25-62). Washington, DC: Island Press.

Jerneck, A., \& Olsson, L. (2008). Adaptation and the poor: Development, resilience and transition. Climate Policy, 8(2), 170-182.

Joseph, J. (2013). Resilience as embedded neoliberalism: A governmentality approach. Resilience, 1(1), $38-52$.

Kellert, S., Longino, H., \& Waters, K. (2006). Introduction. In S. Kellert, H. Longino, \& K. Waters (Eds.), Scientific pluralism, volume XIX of Minnesota studies in the philosophy of science (pp. vii-xxix). Minneapolis, MN: Minnesota University Press.

Klein, R., Nicholls, R., \& Thomalla, F. (2003). Resilience to natural hazards: How useful is this concept? Global Environmental Change Part B: Environmental Hazards, 5(1-2), 35-45.

McLeman, R., \& Smit, B. (2006). Migration as an adaptation to climate change. Climatic Change, 76(1-2), 31-53.

Meerow, S., Newell, J. P., \& Stults, M. (2016). Defining urban resilience: A review. Landscape and Urban Planning, 147, 38-49. doi:10.1016/j.landurbplan.2015.11.011

Newton, A. C. (2016). Biodiversity risks of adopting resilience as a policy goal. Conservation Letters, 9, 369-376. doi:10.1111/conl.12227 
Olsson, C. A., Bond, L., Burns, J. M., Vella-Brodrick, D. A., \& Sawyer, S. M. (2003). Adolescent resilience: A concept analysis. Journal of Adolescence, 26(1), 1-11.

Olsson, L., Jerneck, A., Thoren, H., Persson, J., \& O'Byrne, D. (2015). Why resilience is unappealing to social science: Theoretical and empirical investigations of the scientific use of resilience. Science Advances, 1(4), e1400217.

Orians, G. H. (1975). Diversity, stability and maturity in natural ecosystems. In W. H. van Dobben \& R. H. Lowe-McConnell (Eds.), Unifying concepts in ecology (pp. 139-150). Dordrecht: Springer.

Reid, J., \& Skoglund, A. (2017, March 19). Problematisk forskning. Uppsala Nya Tidning. Retrived from http://www.unt.se/asikt/debatt/problematisk-forskning-4585302.aspx

Rutter, M. (1993). Resilience: Some conceptual considerations. Journal of Adolescent Health, 14(8), 626-631.

Shrader-Frechette, K., \& McCoy, E. (1993). Method in ecology: Strategies for conservation. New York, NY: Cambridge University Press.

Simon, J. (1996). The ultimate Resource 2. Princeton, NJ: Princeton University Press.

Solow, R. (1993). An almost practical step toward sustainability. Resources Policy, 19(3), 162-172.

Strunz, S. (2012). Is conceptual vagueness an asset? Arguments from philosophy of science applied to the concept of resilience. Ecological Economics, 76, 112-118.

Thorén, H. (2014). Resilience as a unifying concept. International Studies in the Philosophy of Science, 28(3), 303-324.

Walker, J., \& Cooper, M. (2011). Genealogies of resilience: From systems ecology to the political economy of crisis adaptation. Security Dialogue, 42(2), 143-160.

Walker, B., \& Salt, D. (2012). Resilience practice. Washington, DC: Island Press.

Williams, B. (2006). Ethics and the limits of philosophy. Abingdon: Routledge.

Zebrowski, C. (2013). The nature of resilience. Resilience, 1(3), 159-173. doi:10.1080/21693293.2013. 804672 